\title{
Acesso livre a publicaçōes e repositórios digitais em ciência da informação no Brasil
}

Mestranda em Ciência da Informação, Departamento e Ciência da Informaçãa e Documentação, Universidiade de Braślila, Campus Universitário Darcy Ribeiro, Asa Norte CEP: $70919-970$ - BRASILLA, DF- Brasil

fernandam@unb.br

Telefone: (61) 92529982

\section{FERNANDO CÉSAR LIMA LEIIE}

Mestrando em Ciência da Informação, Departamento e Ciência da Informação e Documentação, Universiddade de Brasillia, Campus Universitário Darcy Ribeiro, Asa Norte CEP: 70919-970 - BRASILLA, DF- Brasil fernandoc@unb.br Telefone: (61) 8401-3402

\section{MIGUEL ÁNGEL MÁRDERO ARELLANO}

Doutorando em Ciência da Informação, Departamento e Ciência da Informaçãa e Documentaçãa, Universiddade de Brasillia, Campus Universitário Darcy Ribeiro, Asa Norte CEP: 70919-970 - BRASLILA, DF - Brasil arellano@unb.br

Telefone: (61)9692-2368

$\bigcirc$ presente ensaio coloca em perspectiva as transformações na comunicação científica na área da ciência da informação no Brasil e, em particular, aquelas relacionadas às publicações e repositórios digitais de acesso livre. Visando descrever as características das publicações de acesso livre da área, realizou-se levantamento de informações que permitissem observar sua situação atual. Percebem-se manifestações visíveis de parte da comunidade científica em prol da inserção brasileira ao novo paradigma da comunicação científica.

Palavras-chave: Acesso livre; Arquivos abertos; Eprints; Ciência da informação; IBICT; E-LIS. 


\section{Introdução}

A disseminação da informação e do conhecimento em uma comunidade científica depende da rede de comunicação que nela se estabelece, ou seja, como se organizam os seus fluxos de informação e do conhecimento. Muitas comunidades possuem sociedades científicas cuja função é facilitar a comunicação entre seus participantes, promovendo a disseminação do conhecimento científico e o intercâmbio de informações sobre trabalhos e pesquisas em andamento ou concluídos. A interação entre os integrantes dessas sociedades favorece a construção do conhecimento científico.

Ao iniciar o processo de produção de um artigo, o especialista produz esboços de suas idéias para comentários entre seus pares. Este procedimento, originalmente feito somente entre os pesquisadores mais próximos, foi ampliado e dinamizado com o surgimento dos arquivos e repositórios de acesso aberto. Essas tecnologias oferecem uma estrutura mais funcional de organização da literatura do que a organização atual existente no processo de revisão entre pares.

Entre as características destes arquivos/repositórios de acesso aberto estão: i) processo automático de comentários; ii) geração de versões de um mesmo documento: uma vez que o documento seja comentado, o autor pode gerar novas versões do mesmo, atualizando a informação; iii) heterogeneidade dos formatos contemplados no sistema: inicialmente concebido para servir à divulgação de pré-prints', os arquivos de acesso aberto ampliaram sua tipologia de documentos que podem ser arquivados; iv) auto-arquivamento, que devolve o direito ao autor de enviar seu texto para publicação onde este decidir e sem intermediação de terceiros: os documentos eletrônicos são inteiramente gerenciados pelos cientistas e são suficientemente flexíveis tanto para coexistir com os sistemas de publicação tradicional como para auxiliar os editores a se envolverem com algo mais próximo das necessidades dos pesquisadores, e v) interoperabilidade no funcionamento dos arquivos de acesso aberto: os arquivos/repositórios de acesso aberto envolvem um conjunto mínimo de metadados, um tipo de arquitetura subjacente ao sistema, com abertura para a criação de serviços de bibliotecas digitais compartilhados e medidas de uso e de citação.

Na ciência da informação, assim como em outras áreas, é grande o número de pesquisadores que trabalham com mídia digital, adaptando-a ao ensino, aprendizagem e comunicação entre alunos e colegas. Apesar de estes pesquisadores compartilharem suas idéias na Internet, tanto no processo de comunicação formal, publicando em periódicos eletrônicos, quanto na comunicação informal, ainda existem barreiras que os tornam bastante limitados, especialmente no que diz respeito à acessibilidade e discussão entre os pares. Dessa maneira, os periódicos pagos limitam a divulgação do conhecimento a um número restrito de especialistas que podem arcar com os custos de acesso. Além do mais, os periódicos eletrônicos tradicionais não possuem mecanismos que promovam o diálogo entre especialistas de forma a contribuir para o compartilhamento informal de conhecimento e, conseqüentemente, para a melhoria das pesquisas publicadas. Assim, concorda-se com Johnson (2002) quando afirma que o sistema de comunicação científica tradicional limita, mais do que expande, a disponibilidade e legibilidade da maior parte da pesquisa científica.
Cópia do artigo antes de ser avaliado e publicado formalmente 
Uma possível solução para este problema é a construção de arquivos/repositórios de acesso livre baseados em arquivos abertos, onde os conteúdos podem ser acessados sem custos e barreiras de quaisquer naturezas. Os arquivos/repositórios de acesso livre, baseados em arquivos abertos, são interoperáveis e, por esta razão, podem ser acessados por diversos provedores de serviços disponíveis em nível nacional e internacional. Dessa forma, os periódicos eletrônicos, os repositórios institucionais e os repositórios temáticos de acesso livre, aliados à tecnologia de arquivos abertos estão sendo utilizados pelas comunidades científicas para apoiar e tornar mais ampla a divulgação dos resultados das pesquisas bem como maximizar o seu impacto, criando mecanismos para legitimar e estimular a publicação dos trabalhos produzidos.

Especificamente, a situação do acesso livre à produção científica publicada ou não publicada na área da ciência da informação no Brasil está começando a mudar. Há certo consenso no pensamento dos cientistas da informação sobre a importância em disponibilizar a produção científica abertamente e sem restrições, sendo que uma das tarefas atuais é o convencimento aos autores e editores dos principais periódicos da área em usar essas ferramentas. Nesse sentido, a participação do Instituto Brasileiro de Informação em Ciência e Tecnologia - IBICT - tem sido importante no apoio à disseminação do uso de arquivos/repositórios de acesso aberto.

Internacionalmente, o repositório de arquivo de acesso aberto para a produção científica da área da ciência da informação que está recebendo maior adesão por parte dos cientistas da informação é o E-LIS2. Os editores da área de ciência da informação no Brasil estão começando a ter conhecimento do alcance da comunidade E-LIS, como:

- $\quad$ maior visibilidade dos documentos em língua portuguesa na Internet (a produção na área de ciência da informação em português ainda é minoritária);

- compartilhamento da experiência editorial em ciência da informação local e globalmente e,

- $\quad$ auxílio na definição de políticas e estratégias para envolver um número maior de autores.

Este ensaio visa apresentar a implementação e uso dos arquivos/ repositórios digitais de acesso aberto na área da ciência da informação no Brasil, discutindo alguns aspectos técnicos observados no software E-prints, relacionados a sua acessibilidade.

\section{A produção e a comunicação da ciência da informação no Brasil}

${ }^{2}$ E-LIS. E-prints in Library and Information Science.URL: http://eprints.rclis.org
No Brasil, as limitadas fontes bibliográficas específicas para a área de ciência da informação encontram-se dispersas. São várias as dificuldades enfrentadas pelos pesquisadores para terem acesso ao conhecimento acumulado no século passado, e às fontes de informação virtuais temporárias do presente. 
No que diz respeito à produção do conhecimento da área, o Brasil conta com vários cursos de graduação e de pós-graduação em biblioteconomia e ciência da informação, sendo 42 escolas de biblioteconomia ${ }^{3}$ e nove programas de pós-graduação ${ }^{4}$, mas ainda é pequeno o grupo de pesquisadores da área (MUELLER, 2004). O contexto nacional da produção de conhecimento em ciência da informação está concentrado basicamente nas universidades públicas e privadas que mantêm programas de pós-graduação e em uma entidade governamental (IBICT) que trata da informação científica e tecnológica.

De acordo com o Censo $^{5}$ sobre a atividade científica brasileira, realizado em 2000 pelo CNPq, a área de ciência da informação contava com 61 grupos de pesquisa, I 46 linhas de pesquisa e 313 pesquisadores. No ano de 2004, em novo levantamento realizado, portanto quatro anos após o primeiro censo, o número de grupos de pesquisa aumentou para 103, a quantidade de linhas para 230 e o número de pesquisadores para 617. Isso sugere um aumento considerável da atividade científica da área. Entre os estados que se destacam pela sua produção estão o Rio de Janeiro, Bahia, São Paulo, Minas Gerais e o Distrito Federal. Existem apenas duas bibliotecas especializadas na área, e nas bibliotecas predominam os livros e algumas revistas científicas brasileiras indexadas. Percebe-se também a ausência de publicações não tradicionais (filmes, vídeos etc.) e de anais de congressos. Não existe, em nível nacional, uma base de dados de textos completos para recuperar as teses e dissertações da área.

Semelhante às outras áreas do conhecimento, o periódico científico constitui o principal meio de comunicação científica na ciência da informação, sendo responsável pela divulgação da maior parte da produção científica. No contexto brasileiro, as revistas científicas da área possuem algumas similaridades: a maioria disponibiliza texto integral na Internet, possuem um corpo editorial qualificado, usam o sistema de avaliação pelos pares e as sedes são instituições ligadas ao ensino e à pesquisa. É possível observar, ainda, algumas dificuldades como a falta de recursos financeiros, apoio institucional e a irregularidade na freqüência de publicação de alguns periódicos brasileiros da área. Os periódicos brasileiros em atividade são: Ciência da Informação, Perspectivas em Ciência da Informação, Biblos, Cadernos de Biblioteconomia, Informare: Cadernos do Programa de PósGraduação em Ciência da Informação, Transinformação, Revista ACB, Em Questão - Revista da Faculdade de Biblioteconomia e Comunicação, Encontros Bibli, Informação e Sociedade: Estudos, Comunicação e Informação, DataGramaZero, Revista Digital de Biblioteconomia e Ciência da Informação e Documentação, Arquivística. Net, Revista de Biblioteconomia de Brasilia.

Apesar de a maioria dos periódicos brasileiros da área estarem hospedados em instituições de ensino superior, e de os autores dos artigos publicados estarem vinculados a programas de pós-graduação, apenas seis delas possuem algum tipo de política de acesso aberto à informação e permitem o auto-arquivamento livre dos textos já publicados. Mueller e Pecegueiro (200 I), analisando os periódicos brasileiros da área, mostraram que a revista Ciência da Informação tem um papel relevante nesse conjunto de publicações. Este foi a primeiro periódico brasileiro a ter seu conteúdo coletado através do protocolo de Arquivos Abertos OAl-MPH (FONSECA, et al, 2004).

Por outro lado, os cientistas da informação no Brasil contam ainda com canais de comunicação informais. As listas de discussão são veículos muito procurados que permitem uma atualização constante dos temas e problemas
3 Dados da ABECIN. Disponível em: http://www.abecin.org.br/ Escolasbrasil.htm

4 Dados da ANCIB. Disponível em: http://www.ancib.org.br/

${ }^{5}$ Diretório dos grupos de pesquisa do Brasil. Disponível em: http://dgp.cnpq.br/ planotabular/ 
mais relevantes da área, assim como promovem o estreitamento do contato entre especialistas.

Atualmente, existem no Brasil diferentes tipos de listas de discussão utilizadas por profissionais da área da ciência da informação. $\bigcirc$ QUAD. I discrimina as características de dez listas de discussão selecionadas como representativas. Para realizar tal seleção, foram excluídas da relação as listas de discussão que não possuem informações na Internet, que existam há menos de dois anos e que não permitam a possibilidade de réplica pública, assim como as listas de distribuição que tratam apenas do envio de boletins eletrônicos, sem a possibilidade de réplica pública ou interatividade.

\section{QUADRO I}

Listas de discussão da área de ciência da informação brasileiras em 2004

\begin{tabular}{|c|c|c|c|c|}
\hline NOME & $\begin{array}{l}\text { DATA DE } \\
\text { CRIAÇÃO }\end{array}$ & TIPO & USUÁRIOS & $\begin{array}{c}\text { TOTAL DE } \\
\text { ASSINANTES }\end{array}$ \\
\hline BCI-UFSCar & 2002 & Moderada / Restrita & $\begin{array}{l}\text { Alunos e ex-alunos de biblioteconomia da } \\
\text { Universidade Federal de São Carlos - UFScar }\end{array}$ & $|5|$ \\
\hline BIBAMIGOS & 1998 & Não Moderada/Aberta & $\begin{array}{l}\text { Estudantes e profissionais de biblioteconomia e } \\
\text { ciência da informação }\end{array}$ & 670 \\
\hline $\begin{array}{l}\text { BIBLIOTECAS } \\
\text { UNIVERSITÁRIAS }\end{array}$ & 1998 & Moderada/Aberta & Bibliotecários atuantes em IES & 373 \\
\hline INFOLEGIS & 2002 & Moderada/Restrita & $\begin{array}{l}\text { Estudantes e bibliotecários que lidam com } \\
\text { informação jurídica }\end{array}$ & 349 \\
\hline INDEXBR & 2003 & Não Moderada/Aberta & $\begin{array}{l}\text { Estudantes e profissionais de biblioteconomia e } \\
\text { ciência da informação }\end{array}$ & 201 \\
\hline NORMASD & 2003 & Não Moderada / Aberta & $\begin{array}{l}\text { Estudantes, bibliotecários, arquivistas, editores e } \\
\text { escritores }\end{array}$ & 209 \\
\hline GBICSSC & 2001 & Moderada/Restrita & $\begin{array}{l}\text { Grupo de Bibliotecários de Informação em } \\
\text { Ciências da Saúde }\end{array}$ & 35 \\
\hline BIBLIOTECARIOS & 2000 & Moderada / Restrita & $\begin{array}{l}\text { Estudantes e profissionais de biblioteconomia e } \\
\text { ciência da informação }\end{array}$ & 810 \\
\hline $\begin{array}{l}\text { BIBLIOTECAS } \\
\text { ESCOLARES }\end{array}$ & 2000 & Moderada / Restrita & Bibliotecários & |4| \\
\hline BIB_VIRTUAL & 1996 & Moderada/Aberta & Profissionais da ciência da informaçã̃o & 600 \\
\hline
\end{tabular}

${ }^{6}$ Bib virtual: Lista de discussão gerenciada pelo IBICT. Disponível em: https:// listas.ibict.br/mailman/istinfo/bib_virtual
Como se pode observar, a lista Bib_virtual ${ }^{6}$ é a mais antiga entre as listas de discussões brasileiras da área. Esta antiguidade talvez possa ser explicada pelo fato de a lista ser a única que utiliza um servidor de listas institucional (IBICT). Outra característica comum a este conjunto de listas é que ela conta com a figura do moderador, mesmo que sua tarefa seja somente a de receber os pedidos de inscrição. Em cinco delas, as mensagens são enviadas diretamente para todos os assinantes, sendo restrito a eles o envio e consulta às mensagens nas outras cinco.

Estes canais de comunicação não estruturados permitem a formação de comunidades virtuais de aprendizagem, onde pessoas motivadas, com interesses comuns, são estimuladas à busca do conhecimento. No Brasil, as 
listas são um dos elementos da comunidade de aprendizagem colaborativa à distância via Internet (SOARES; AMARAL, 2004), onde o requisito principal é a pré-disposição pessoal para o compartilhamento de informação e conhecimento.

\section{Arquivos abertos em ciência da informação no Brasil}

O IBICT vem acompanhando a iniciativa dos arquivos abertos desde o ano 2000. O Instituto criou o Laboratório de Tecnologias da Informação - LTI- para o estudo e avaliação de softwares e ferramentas para o desenvolvimento de serviços e produtos de biblioteca digital. No primeiro ano, o trabalho de prospecção esteve centrado no levantamento bibliográfico para a criação de um guia de fontes de informação de bibliotecas digitais, em pesquisas sobre serviços de referência virtual e na concepção do Projeto Biblioteca Digital Brasileira.

Uma das primeiras ferramentas testadas no Laboratório foi o software Phronesis da Universidade de Monterrey (México), que foi traduzido e usado para disponibilizar os textos completos do evento XVII Congresso Brasileiro de Biblioteconomia e Documentação, realizdo em 2000. Um ano mais tarde, o software foi testado novamente na criação do primeiro repositório digital da revista Ciência da Informação, na primeira interface Web da Biblioteca Digital Brasileira - BDB. A partir de um conhecimento mais amplo da iniciativa dos arquivos abertos, do padrão de metadados Dublin Core e da linguagem $X M L^{8}$, verificou-se que o software Phronesis não incluía mecanismos de interoperabilidade. Foram iniciados, paralelamente, estudos sobre o software EPrints da Universidade de Southampton (Inglaterra) ${ }^{9}$. $\bigcirc$ software EPrints como um mecanismo de comunicação entre pesquisadores, foi contemplado para ser traduzido e repassado às comunidades científicas brasileiras. Solicitou-se ao IBICT, então, o compartilhamento de sua experiência com outras instituições de ensino e pesquisa, delineando-se, com algumas delas, acordos e condições de colaboração para a implementação de projetos de arquivos de acesso aberto.

A primeira instituição a adotar o sistema para criação de repositórios temáticos usando o EPrints foi a Sociedade Brasileira de Genética (http:// sbg.ibict.br). A segunda comunidade científica a adotá-lo foi a Sociedade Brasileira de Estudos Interdisciplinares da Comunicação (Intercom), que criou o repositório Arena Científica (http://arena.portcom.intercom.org.br/) para os pesquisadores lusófonos da área das ciências da comunicação. Este repositório está sendo utilizado, atualmente, pelos estudantes de pósgraduação, docentes e pesquisadores desta área como um dos módulos do Portal PORTCOM (FERREIRA, 2002).

Desde o início dos trabalhos colaborativos nos sub-projetos da Biblioteca Digital Brasileira, o IBICT disseminou informação sobre estas ferramentas nas páginas do seu Portal. Nas páginas do Laboratório de Tecnologias da Informação estão expostas informações sobre ferramentas open source, sendo algumas customizadas para o Brasil pelo Instituto ou por instituições parceiras (IBICT, 2005). As atividades relacionadas à disseminação e orientação das sociedades científicas brasileiras, quanto ao uso do software EPrints, têm sido realizadas permanentemente pelos técnicos do Laboratório em eventos nacionais e internacionais.Além disto, os técnicos têm acompanhado a sua implementação

7 Disponível em: http://phronesis.cide.edu/ bib/

${ }^{8}$ Extensible Markup Language

${ }^{9}$ Disponível em: http://www.eprints.org 
em várias instituições de ensino e pesquisa, como PORTOCOM, USP, UFPR, EMBRAPA, Faculdade Cenecista Presidente Kennedy, entre outros ${ }^{10}$.

No ano de 2003, o IBICT teve conhecimento do trabalho do Public Knowledge Project - PKP -, da University of British Columbia (Canadá)" , e analisou o software Open Journal Systems que foi traduzido como Sistema Eletrônico de Editoração de Revistas -SEER-. Este sistema permite o gerenciamento do workflow de uma publicação científica e utiliza padrões de interoperabilidade da $\bigcirc A$.

$\bigcirc$ uso destes padrões pelo SEER torna os periódicos que o adotam integrados ao crescente número de revistas científicas que seguem a iniciativa de arquivos abertos. Adaptado para a realidade dos periódicos brasileiros, o SEER é destinado originalmente a centros de pesquisa, universidades e editores científicos, mas pode ser utilizado por qualquer instituição ou particular que se interesse em fundar e manter uma publicação eletrônica de acesso aberto.

Atualmente, sete revistas da área de ciência da informação já usam o SEER: Ciência da Informação(http://www.ibict.br/cienciadainformacao/), Revista Digital de Biblioteconomia e Ciência da Informação (http:// server0l.bc.unicamp.br/seer/ojs/), Arquivística.net (http:// www.arquivistica.net/ojs/index.php), Perspectivas em Ciência da Informação (http://www.eci.ufmg.br/pcionline), Revista ACB (http:// www.acbsc.org.br/revista/ojs/), Transinformação (http://revistas.puccampinas.edu.br/transinfo/index.php), Biblos - Revista do Departamento de Biblioteconomia e História (http://www4.furg.br/ojs/biblos/ojs/index.php) e a multidisciplinar ETD - Educação Temática Digita/(http://I 43. I 06.58.55/ revista/index.php). A Revista de Biblioteconomia de Brasília está iniciando a sua adoção. Com a adoção do SEER esses periódicos podem ser considerados não apenas como publicações que seguem o Green Road do Movimento do Acesso Aberto, permitindo que seus autores depositem seus artigos em repositórios digitais em qualquer parte do mundo, mas também que eles seguem a Gold Road, ou seja, publicações totalmente de acesso aberto (HARNAD et alli., 2004). $\bigcirc$ IBICT considera essas revistas como a base para a criação futura de um provedor de serviços usando como modelo o Harvester do Public Knowledge Project(PKP).

Em 2004 foi lançado o repositório EPrints - Diálogo Científico em Ciência da Informação (http://www. dici.ibict.br), abrindo-se um espaço para que os autores da área da ciência da informação no Brasil pudessem autoarquivar sua produção e assim garantir o acesso aberto e permanente à informação. Procurando a sua adoção por parte dos pesquisadores da área, foi inserida a produção científica dos especialistas do IBICT no sistema, e solicitado aos editores das revistas Educação Temática Digital, Revista Digital de Biblioteconomia e Ciência da Informação, DataGramaZero, Arquivística.net e a Revista de Biblioteconomia de Brasilia que depositassem os trabalhos publicados nas respectivas revistas. A revista Ciência da Informação sugere aos autores que não tiveram seus trabalhos aceitos em algum periódico que submetam os pré-prints ao repositório

${ }^{10}$ Repositórios brasileiros que usam Eprints URL:http://www.ibict.br/ secao.php?cat=Diálogo\%20Científico/ Repositorios

" URL: http://www.pkp.ubc.ca/ojs/

12 Disponível em: http://www.dspace.org
Diálogo Científico, e vários profissionais aceitaram que seus trabalhos publicados fossem nele arquivados.

Ainda em 2004, o IBICT iniciou os trabalhos de adaptação do software DSpace do Massachusetts Institute of Technology - MIT - ${ }^{12}$ para a criação do Repositório Digital Institucional - RIDI -. Os trabalhos com o Dspace fortaleceram o estabelecimento de uma política institucional de preservação 
digital, que o Instituto já havia começado a detalhar desde 2002, junto a vários especialistas da área. Inicialmente foi solicitada, para fins de análise, uma cópia da versão traduzida para o português pela Universidade do Minho em Portugal. Posteriormente, formalizou-se a versão customizada para o português do Brasil em parceria, novamente, com a equipe da PORTCOM.

A primeira versão do RID (https://repositorio.ibict.br/ridi) encontrase em fase de testes, como um arquivo digital institucional que sirva como mecanismo de armazenamento, disseminação e acesso à produção técnicocientífica dos funcionários do IBICT. Espera-se, também, que a adoção do RID produza uma visibilidade e impacto maiores do conhecimento produzido na instituição, assim como uma estratégia de preservação digital da memória científica da área.

No momento, estão sendo analisadas as possibilidades de integração dos três repositórios da área da ciência da informação mantidos pelo IBICT (DiCi, SEER e RID) e do conjunto de teses e dissertações da área que já constam na Biblioteca Digital de Teses e Dissertações -BDTD-. Cada repositório e o conjunto selecionado da BDTD atuarão como provedores de dados com plataformas distintas, para serem compilados pelo protocolo OAl-MPH e coletados por um provedor de serviços da produção em ciência da informação no Brasil.

Com o objetivo de descrever as características dos periódicos científicos eletrônicos brasileiros de acesso livre da área, foi realizado levantamento de informações que permitissem observar a situação atual das publicações. As informações foram coletadas nos sítios dos próprios periódicos durante o mês de dezembro de 2005 e janeiro de 2006, e podem ser observadas no QUAD. 2. Os dados dizem respeito ao nome do periódico, região de publicação, a instituição vinculada, a presença do ISSN - International Standard Serial Number - a periodicidade, a presença de conselho editorial, a presença de padrões de normalização para publicação, a presença de revisão pelos pares, a tecnologia utilizada e a publicação paralela ou não de versão impressa. Tais atributos permitiram caracterizar de maneira geral o universo brasileiro de periódicos de acesso livre em ciência da informação.

\section{A ciência da informação e o acesso livre no Brasil}

No contexto atual, observam-se importantes mudanças no sistema de publicação científica. Se por um lado a Internet e as novas tecnologias da informação e comunicação têm oferecido os meios tecnológicos para viabilizar estas transformações, por outro, o mundo da ciência tem buscado novas estratégias de divulgação e acesso dos resultados de pesquisas.

Entretanto, é fato que nenhum usuário ou biblioteca pode ter acesso a todos os 24.000 periódicos científicos existentes no mundo ${ }^{13}$. Considere-se, ainda, que o número de artigos científicos publicados por pesquisadores de países latino-americanos quase triplicou em menos de dez anos ${ }^{14}$. $\bigcirc$ acesso livre a publicações científicas é necessário não apenas aos leitores, mas também aos autores, pois se as instituições nas quais eles trabalham não possuem os meios para acessar esses periódicos, por conseqüência, o potencial de impacto da sua pesquisa é diminuído.

\footnotetext{
13 As bibliotecas começaram a vislumbrar as vantagens das publicações de acesso aberto graças a serviços tais como: $\mathrm{Mr}$ Serials Process, Index Morganagus e DOAJ.

${ }^{14}$ National Science Foundation URL: http:/ Mww.nsf.gov
} 


\begin{tabular}{|c|c|c|c|c|c|c|c|c|c|c|c|c|}
\hline 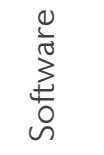 & 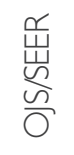 & 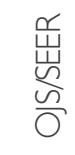 & 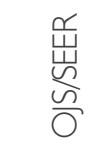 & 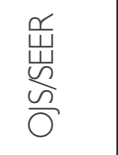 & 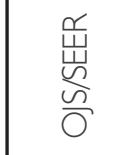 & 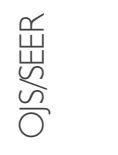 & 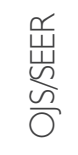 & 旁 & 号 & 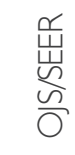 & 站 & 弯 \\
\hline 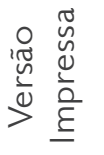 & $\frac{\pi}{2}$ & $\underline{\varepsilon}$ & $\underline{E}$ & 尊 & $\frac{\stackrel{0}{\pi}}{Z}$ & $\frac{0}{2 \pi}$ & $\underline{\varepsilon}$ & $\frac{0}{2 \pi}$ & $\frac{i 0}{Z}$ & $\frac{\pi}{Z}$ & $i \frac{\varepsilon}{n}$ & $\underline{\varepsilon}$ \\
\hline 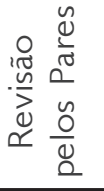 & $\underline{E}$ & $\underline{\xi}$ & $\underline{E}$ & $\underline{\varepsilon}$ & E & $\varepsilon$ & $\underline{\varepsilon}$ & $\underline{E}$ & $\underline{\varepsilon}$ & $i \frac{\varepsilon}{n}$ & $i \frac{\varepsilon}{n}$ & $\underline{\varepsilon}$ \\
\hline $\begin{array}{l}\frac{\mathbb{0}}{\mathbb{J}} \\
\frac{\mathbb{N}}{\tilde{N}} \\
\text { है } \\
Z\end{array}$ & E & $\underline{\varepsilon}$ & $i$ & $i \frac{\varepsilon}{n}$ & $\underline{\xi}$ & $i \underline{\underline{n}}$ & $\underline{\xi}$ & $\underline{\xi}$ & $i \frac{\xi}{n}$ & $i \underline{n}$ & $\underline{\varepsilon}$ & $\underline{\xi}$ \\
\hline 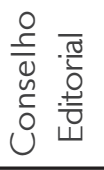 & E & $\underline{\varepsilon}$ & $i$ & E & $\underline{E}$ & $i \frac{\xi}{n}$ & $\underline{E}$ & $\underline{E}$ & $\stackrel{\varepsilon}{n}$ & $\underline{E}$ & 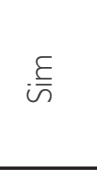 & $\underline{\varepsilon}$ \\
\hline $\begin{array}{l}\frac{0}{0} \\
\frac{\pi}{0} \\
\frac{\bar{v}}{\overline{0}} \\
\frac{.0}{\overline{0}} \\
0\end{array}$ & 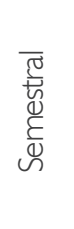 & 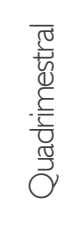 & 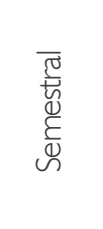 & 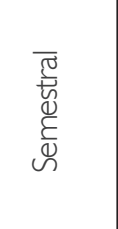 & 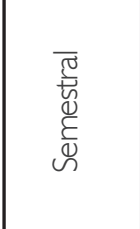 & 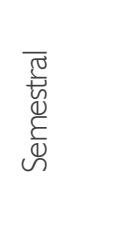 & 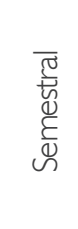 & 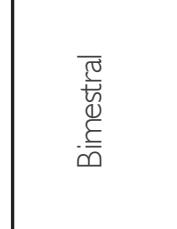 & 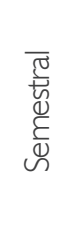 & 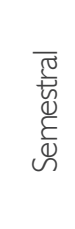 & 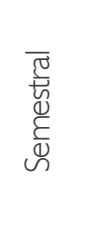 & 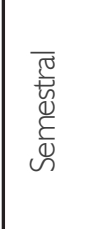 \\
\hline $\begin{array}{l}Z \\
\underline{\sim}\end{array}$ & $\frac{\varepsilon}{n}$ & $\underline{\varepsilon}$ & 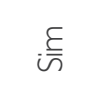 & $\underline{\varepsilon}$ & $\underline{\varepsilon}$ & $\underline{\varepsilon}$ & $i \frac{\varepsilon}{n}$ & $\underline{\varepsilon}$ & $\frac{2}{Z}$ & 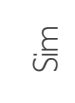 & $\underline{\varepsilon}$ & $i \varepsilon$ \\
\hline 芯 & $\begin{array}{l}\frac{\sqrt{0}}{000} \\
\frac{0}{0} \\
. \frac{3}{3} \\
\frac{0}{4}\end{array}$ & 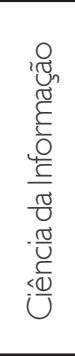 & 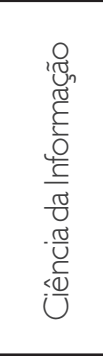 & 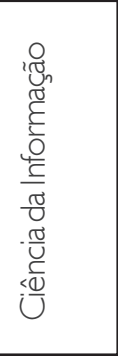 & 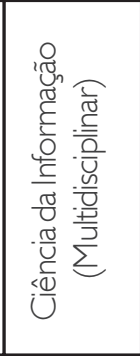 & 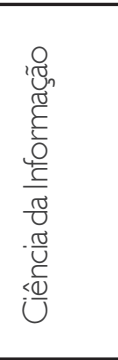 & 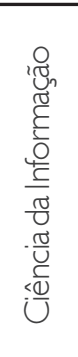 & 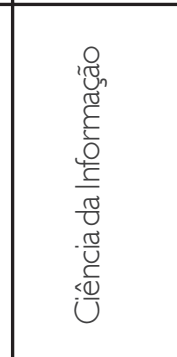 & 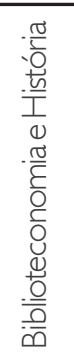 & 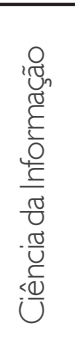 & 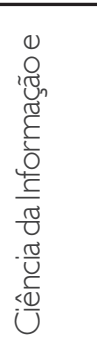 & 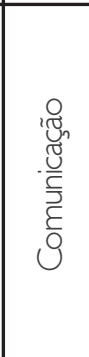 \\
\hline 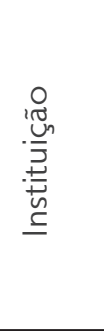 & $\frac{\stackrel{O}{\underline{Y}}}{\bar{J}}$ & $\frac{t}{\underline{\theta}}$ & $\sum_{\stackrel{M}{J}}^{\cup}$ & 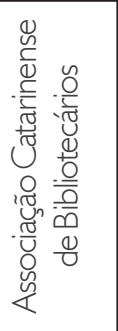 & 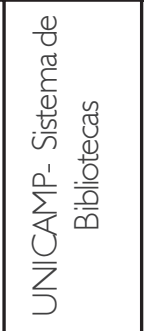 & $\frac{\sum_{j}^{0}}{\sum_{J}}$ & 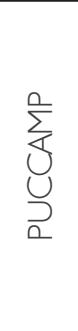 & 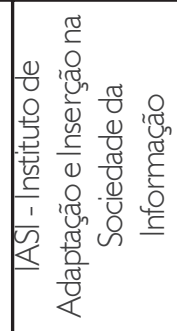 & $\begin{array}{l}\text { u } \\
\text { 岁 }\end{array}$ & $\begin{array}{l}\mathscr{\sim} \\
\stackrel{\sim}{J}\end{array}$ & $\begin{array}{l}\infty \\
\stackrel{0}{0} \\
\frac{4}{J}\end{array}$ & $\begin{array}{l}\mathscr{U} \\
\stackrel{Y}{4} \\
\stackrel{4}{J}\end{array}$ \\
\hline 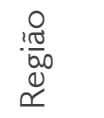 & 岗 & $\Theta$ & 岗 & $\bar{\Xi}$ & 岗 & 岗 & 岗 & 岗 & $\backsim$ & $\sim$ & 㞱 & $\sim$ \\
\hline $\begin{array}{l}\stackrel{0}{E} \\
\text { Z }\end{array}$ & 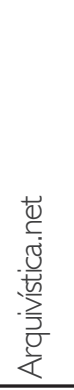 & 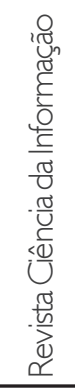 & 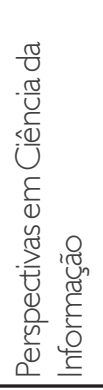 & 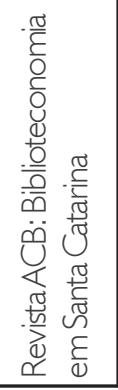 & 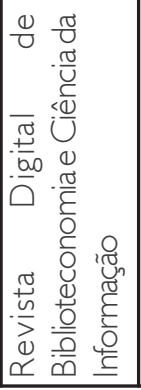 & 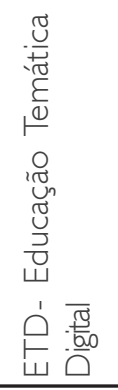 & 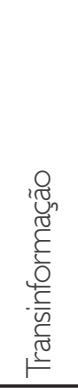 & 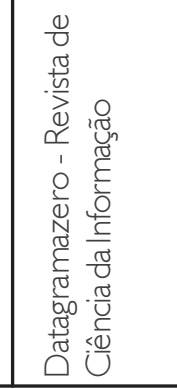 & 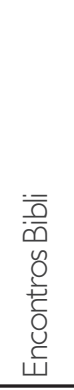 & $\frac{\stackrel{0}{0}}{\frac{0}{0}}$ & 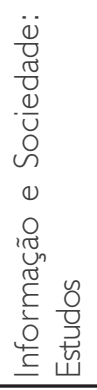 & 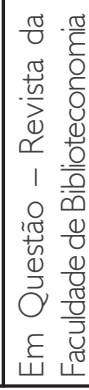 \\
\hline
\end{tabular}


Não se considera que a prática de publicar deva ser mudada, mas que a prática de arquivamento deva ser um suplemento à prática de publicação existente. Cada área do conhecimento deve ter uma prática de arquivamento diferente, por esta razão, a adoção dos periódicos de acesso livre e repositórios institucionais/temáticos deve ser adequada às práticas de cada comunidade científica. Adotando-se esse novo modelo de publicação, o trabalho que envolve a criação, manutenção e publicação de sistemas de arquivamento on-line é reduzido.

O estudo descritivo realizado permitiu a observação de uma série de atributos que caracterizam, de maneira geral, o atual estado dos periódicos eletrônicos de acesso livre em ciência da informação no Brasil. Do total de 16 periódicos científicos nacionais da área, 12 são eletrônicos, sendo que seis são exclusivamente eletrônicos e os outros cinco mantém, além da versão eletrônica, publicação impressa em paralelo. Todos os periódicos eletrônicos possuem ISSN. Percebe-se, ainda, que oito estão vinculados a instituições de ensino, sendo que, dentre estes, cinco estão ligados a programas de pós-graduação em ciência da informação. No que diz respeito à periodicidade, a maioria dos periódicos analisados, nove, publica seus números semestralmente. Todos os periódicos eletrônicos de acesso livre possuem conselho editorial, regras de normalização para publicação e adotam o sistema de avaliação pelos pares. Quanto à tecnologia utilizada, oito periódicos fazem uso do Sistema Eletrônico de Editoração de Revistas, o Open Journal System.

Como já foi apontado, durante os últimos anos o IBICT vem reunindo esforços na promoção do uso de arquivos de acesso aberto, participando de vários eventos nacionais e internacionais, publicando artigos científicos sobre o tema e agregando-se a instituições e projetos que declarem seu apoio ao acesso aberto aos dados das pesquisas financiadas com fundos públicos. $\bigcirc$ Brasil já se encontra entre o seleto grupo de países que contam com um número considerável de repositórios institucionais de acesso aberto. ${ }^{15}$

É importante mencionar que, internacionalmente, o arquivo de acesso aberto para a produção científica da área da ciência da informação que está recebendo maior adesão por parte dos cientistas da informação é o repositório E-LIS (2005). O Brasil participa desta iniciativa integrando os conteúdos em língua portuguesa dos diferentes arquivos/repositórios de acesso aberto nacionais neste provedor de informação científica. Da mesma forma, uma importante iniciativa, em nível internacional, é o Directory of Open Access Journals - DOAJ (http://www. doaj.org/), que conta atualmente com 495 periódicos científicos de texto completo e acesso aberto e 55 desse total são da área de ciência da informação.

Entretanto, a evidência de que a iniciativa está, de fato, funcionando seria o fato dos pesquisadores realmente depositarem seus documentos. A maioria dos pesquisadores desconhece como colocar à disposição seus trabalhos avaliados permitindo um maior impacto da pesquisa através do auto-arquivamento. A forma como os repositórios de acesso aberto são recebidos pelas comunidades científicas depende de observar como os seus membros percebem os benefícios ao ter sua produção científica publicada por meio do auto-arquivamento.

No Brasil, a comunidade de pesquisadores da ciência da informação ainda não elaborou qualquer plano de ação a fim de que as
${ }^{15}$ Registro do Eprints disponível em: http://archives.eprints.org/ eprints.php?action $=$ browse 
instituições reconheçam o valor da produção científica disponibilizada abertamente. Não se conta localmente com qualquer política institucional para a criação e manutenção de repositórios de acesso aberto. Contudo, o IBICT está promovendo o uso destes repositórios entre os discentes dos Programas de Pós-Graduação em Ciência da Informação e com os membros da Associação Nacional de Pesquisa e Pós-Graduação em Ciência da Informação - ANCIB. Dessa maneira, eles participarão do esclarecimento de seus colegas quanto aos benefícios dos repositórios institucionais. Além disso, a disseminação do conteúdo dos periódicos brasileiros da área no ELIS é fundamental para a visibilidade da produção científica nacional. Esperase contar com a colaboração da equipe do E-LIS na definição de políticas e estratégias para envolver mais autores no arquivamento público da produção científica da área.

Um aspecto pouco abordado na divulgação dos repositórios da ciência da informação tem sido a importância dos pré-prints e dos comentários dos pares. Estes documentos são essenciais para o especialista envolvido na pesquisa. Os pesquisadores procuram constantemente conhecer aquilo que está sendo gerado em termos de inovação, o que os leva a buscar uma literatura ainda não publicada e totalmente disponível. As novas tecnologias da informação possibilitaram um aumento progressivo da produção de pré-prints e relatórios de pesquisa, e, por conseqüência, uma demanda cada vez maior por mecanismos que viabilizem a divulgação desta forma de informação no menor prazo possível.

Controlada a sua disseminação nos arquivos de acesso livre, os pré-prints e os comentários dos pares são imprescindíveis para alcançar a solidificação desses repositórios. A ausência do item comentários nas estratégias de busca do software EPrints faz prevalecer a utilização dos repositórios preferencialmente para consulta/pesquisa de informação e não para publicação/arquivamento de comentários e outros tipos de documento.

$\bigcirc$ trabalho colaborativo do IBICT com o E-LIS e com outras instituições de ensino no Brasil, assim como a possibilidade de expansão para mais periódicos da área, tem oferecido elementos para orientar o processo de formação de mais arquivos de acesso aberto que sirvam como alternativa para os fluxos de informação tradicionais da comunidade científica da ciência da informação.

\section{Considerações finais}

Devido à introdução e adoção das tecnologias de informação, o sistema de comunicação científica tornou-se alvo constante de inovações. Essas transformações incidem tanto na comunicação informal, sobre a qual há uma diversidade de estudos que revelam que a aceitação de inovações tecnológicas dá-se de maneira rápida e homogênea, quanto nos veículos de comunicação formal, onde questões como diferenças disciplinares e regionais exercem uma maior influência. Assim, o processo de comunicação formal, e, de modo mais intenso o periódico científico, passa por muitas transformações tecnológicas. Isso permitiu o surgimento do periódico científico eletrônico, um indício evidente das transformações no sistema formal de comunicação científica. 
Atualmente, o movimento do livre acesso ao conhecimento científico tem despertado grande interesse de diferentes áreas do conhecimento, especialmente da ciência da informação. Como tópico de estudo, o acesso livre ao conhecimento científico tem suscitado intensas discussões em nível nacional e internacional. Especialmente por conta do IBICT e de um grupo pequeno de pesquisadores da ciência da informação e de outras áreas que se dedicam ao tema, o Brasil vem se inserido gradativamente no novo paradigma da comunicação científica.

A disseminação e adoção de ferramentas baseadas no protocolo OAl-PMH ${ }^{16}$, o apoio declarado como no Manifesto Brasileiro de apoio ao Livre Acesso à Informação Científica (http://www.ibict.br/openaccess/ arquivos/manifesto.htm) e na Carta de São Paulo (http:// www.acessoaberto.org/carta_de_sao_paulo_acesso_aberto.htm), a recorrente discussão em congressos e seminários, são exemplos de manifestações visíveis de parte da comunidade científica brasileira em prol da inserção brasileira ao novo paradigma da comunicação científica.

Muito embora todas essas ações sejam indispensáveis, alguns outros fatores são determinantes para o sucesso da iniciativa. Esses fatores dizem respeito à participação ativa das instituições de ensino e pesquisa, das sociedades científicas, bem como dos editores científicos e das agências de fomento.

Nesse contexto, a adesão das agências de fomento ao movimento é um passo imprescindível, sem o qual, ao longo do tempo, tornar-se-á fadado ao insucesso todo e qualquer esforço. A razão disso é explicada pela lógica do próprio sistema científico, uma vez que são as agências públicas de fomento que financiam amplamente a pesquisa científica, e, por esta razão, são elas que detêm poder de incentivo tanto para a publicação científica em mecanismos de acesso livre, quanto para o reconhecimento da literatura científica publicada nesses meios, para efeitos de avaliação da produção científica. As agências brasileiras precisam manifestar o seu apoio, como a Wellcome Truste a House of Commons na Inglaterra, e a National Institutes of Health nos Estados Unidos o fizeram. Da mesma forma, é necessário que as agências atuem no delineamento de políticas que norteiem as ações da comunidade científica no que diz respeito ao fomento para a criação de repositórios de acesso livre nas instituições de ensino e pesquisa, como ressalta Costa (2005).

Por fim, é notória a emergência de um novo paradigma no sistema global de comunicação da ciência. $\bigcirc$ Brasil vem se inserindo nesse novo contexto e acompanhado tais mudanças, haja vista a crescente adesão de publicações científicas eletrônicas ao novo modelo de comunicação científica e o surgimento de repositórios institucionais/temáticos. No entanto é importantíssima a participação de todos os elos da comunidade científica, em seu sentido mais amplo, como editores científicos, instituições acadêmicas (universidades, institutos e centros de pesquisa, associações científicas e outros), agências de fomento e pesquisadores. As recomendações à comunidade científica feitas pelo Manifesto Brasileiro de apoio ao Acesso Livre à Informação Científica, fundamentado nos termos da Declaração de Berlim, podem ser acessadas no http:// www.ibict.br/openaccess/arquivos/manifesto.htm.
16 DSpace (http://www.dspace.org); Archimede(http://archimede.bibl. ulaval.ca/); CDSware (http://cdsware. cern.ch); Fedora (http://www.fedora.org); i-Tor (http://www.i-tor.org/en/toon) (MÁRDERO ARELLANO; MORENO: CHAGAS, 2005), além de OJS (http:// pkp.ubc.ca/ojs) e Open Conference System - OCS (http://pkp.ubc.ca/ocs), para editoração eletrônica de anais de evento. 


\section{Open access to journals and digital repositories in Library and Information Science in Brazil}

This essay focuses on the scientific communication transformations within the Information Science in Brazil, particularly those related to open access to digital journals and repositories. It is aimed to describe the characteristics of the open access Library and Information Science journals. The present context of Brazilian publications was examined collecting data through a survey procedure. Results showed that Brazilian scientific community is motivated in getting into the new scientific communication paradigm.

Key-words: Open access; Open archives; Eprints; Information Science; IBICT; E-L/S.

\section{Referências}

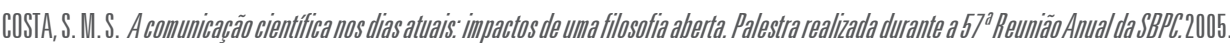
Disponivel em httpp//wwww.reacao.com. br/programa_shpc57ra/shpccontrole/textoss/selycosta.httm \# _ftn1.Acesso em set.2005.

E-LIS.E.-prints in Library and lnformation Science. Disponivel em: < http://eprints.rclis.org > Acesso em: 15 out. 2005.

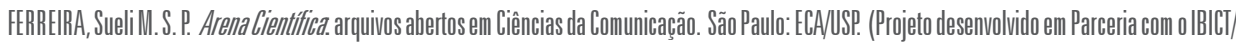
Programa Open Archivess. Versão de nov. 2002.

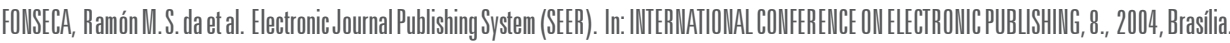
Disponivel em: $<$ http://portal.cid.unh.br/elpub/viewabstract.php? id = 36 > Acesso em 20 out. 2005 .

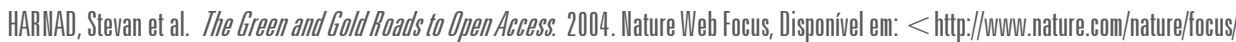
accessdebate/21.html > Acesso maio 2005.

IBICT. Instituto Brasileiro de Informação em Ciência e Tecnologia. Laboratórí de Tecnnologia. Disponivel em: < hittp://www.hibit.br/ secao.php?cat = Laboratório > . Acesso em 25 set. 2005.

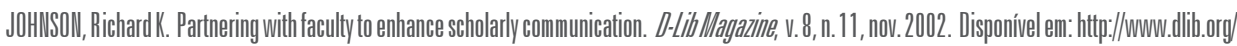
dilib/november[2/johnson/11johnson. httm. Acesso em 23 maio 2005.

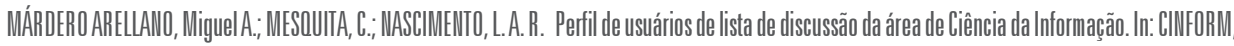
6., 2005, Salvador, Bahia. Anais.... Salvador: UFBA, 2005

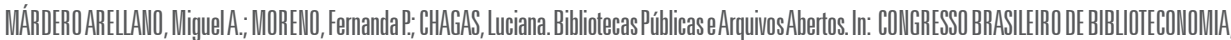

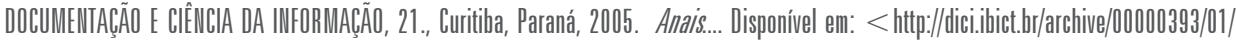
Miguel_Biblioteca_Bigital.poff>. Acessoem 15 dez.2005.

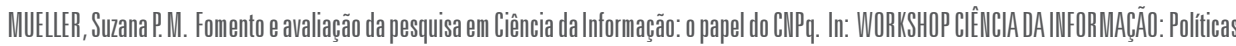

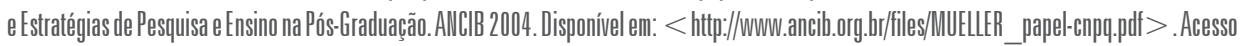
em 20 out. 2005

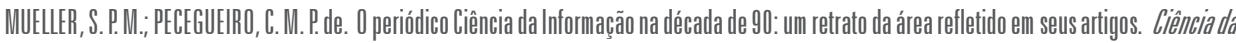
Inforrmagää, Brasilia, v. 30, n. 2, p. .77-63, maio/ago. 2001.

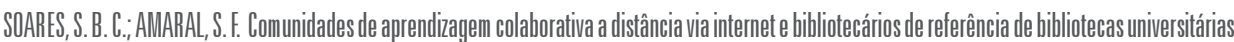

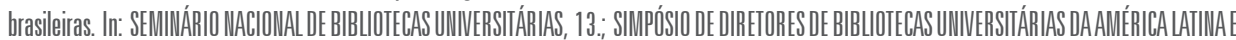

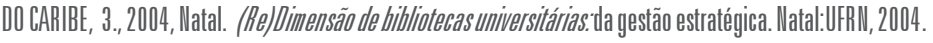

